\title{
DROUGHT RESISTANCE AND PRODUCTIVITY OF WHEAT AND SOYBEAN ISOGENIC LINES WITH DIFFERENT PHOTOPERIODIC SENSITIVITY
}

\author{
Olga Avksentiieva \\ Department of Plant Physiology and Ecology \\ Educational and Scientific Centre "Institute of Biology and Medicine" \\ Taras Shevchenko National University of Kyiv \\ 64/13 Volodymyrska str., Kyiv, Ukraine, 01601 \\ Department of Physiology and Biochemistry of Plants and Microorganisms \\ V. N. Karazin Kharkiv National University \\ 4 Svoboda sq., Kharkiv, Ukraine, 61022 \\ avksentyeva@univer.kharkov.ua \\ Nataliia Taran \\ Department of Plant Physiology and Ecology \\ Educational and Scientific Centre "Institute of Biology and Medicine" \\ Taras Shevchenko National University of Kyiv \\ 64/13 Volodymyrska str., Kyiv, Ukraine, 01601
}

\begin{abstract}
The results of the study of drought tolerance of isogenic (NILs - near isogenic lines) by genes PPD (photoperiod) wheat lines and isogenic by genes EE (early maturation) soybean lines, that control the photoperiodic sensitivity are presented. In field experiments the photoperiodic sensitivity of the lines when grown under natural long days (16 hours at a latitude of Kharkov) and under artificial short-day (9 hours) is determined. The results showed that line PPD-D1A and PPD-Ala wheat and soybean lines $L 71-920$ had a weak photoperiodic sensitivity (weak PPDS) and line PPD-Bla wheat and soybean lines $L$ 71-920 - strong photoperiodic sensitivity (strong PPDS). Wheat and soybean lines with weak PPDS were more productive. When simulating drought action on seed germination (20\% strength mannitol solution - rapid method), it was showed that the seeds of soybean and wheat lines with weak PPDS have a higher germination than seeds of the lines with strong PPDS. When simulating soil drought (30 \% FMC - field moisture capacity of the soil) under growing experiment, it was revealed that the biomass accumulation indices of plants, leaf relative water content (RWC) and proline content in leaves lines with weak PPDS were higher than in the photoperiodic lines with strong PPDS. So, all used methods for determining drought tolerance showed that the low photoperiodic sensitivity lines are more resistant to drought.

It is assumed that wheat genes $P P D$ and soybean genes $E E$ can participate in the formation of resistance to drought. Genotypes with low photoperiodic sensitivity should be used in breeding soybean and wheat drought resistance.

Keywords: soft wheat Triticum aestivum L., soybean Glycine max (L.) Merr, nearly isogenic lines (NILs), the photoperiodic sensitive (response), the pace of plant development; drought resistance.
\end{abstract}

\section{Introduction}

In the global climate change conditions, the main factor in reducing the field crops productivity is drought [1]. The study of molecular-genetic mechanisms of stress tolerance, including resistance to drought, deals with a number of works $[2,3]$. There have been found certain changes at the level of the genome and QTL (Quantitative Trait Loci) [4, 5], but the effects of these changes are not clear at the level of phenotypic expression characteristic of drought resistance. Apparently, the detection of these effects is important to establish that drought complex quantitative trait which expression is not controlled by a single gene or QTL (effects of which coordinately appear during the ontogenesis adequately to the change of intensity level of environmental factors), but the systems of genes, determining their different effects at the different stages of plants ontogeny. Probably, such a system could be genes PPD (photoperiod) and $V R N$ (vernalization) in wheat [6], while the soybean genes of the $E$-series (early maturity) [7]. These genetic systems, controlling the pace of plant development, are probably involved in the regulation of physiological and biochemical 
processes changes of an adequate level of environmental factors intensity that could determine the resistance to abiotic stresses, including drought. Plants have a number of resistance mechanisms to lack of moisture in the soil, accompanied by high temperatures and low humidity [8].

Among these mechanisms the ability of plants to drought avoidance is important. It is associated with a change in the pace of development - the duration of the individual phases of ontogeny and duration of the growing season as a whole under the influence of environmental factors. The length of photoperiod and temperature are the most important of these factors. It is known that the duration of ontogeny, the pace and the speed of plant development are evolutionarily established, hereditary fixed traits that are controlled by multiple genetic systems. In the most valuable food crop, soft wheat Triticum aestivum L. there is a system of genes $V R N$ (vernalization), determining the pace and type of development (summer or winter) $[9,10]$. In addition, there is a system of $P P D$ (photoperiod) genes, which determines the degree of sensitivity and/or insensitivity to photoperiod [11].

In soybean Glycine $\max ($ L.) Merr. - the most common high-protein oilseed in the world, widely used in the technical, food and feed purposes - the leading role in the regulation of the development speed belongs to the system of genes $E E$ (early maturity), determining the length of the period before flowering and photoperiodic sensitivity [12]. The productivity of these crops depends on the implementation of genetically inherent yield potentialities, as well as the influence of specific climatic conditions, existing at a certain stage of plant ontogeny, which is determined by the genes, controlling the pace of development.

Genetic effects of these systems on a number of agronomic and physiological and biochemical traits - the structure of crop productivity, protein and oil content of grain - have been well studied $[12,13]$. However, the literature contains no data of the study of these gene systems effects, controlling the pace and type of development of drought tolerance of these important crops. In the current conditions of climate change, followed by regular droughts and extremely high temperatures, it seems urgent to study the effects of these genetic systems that control the development pace of soft wheat and soybean plants at the level of their drought tolerance.

\section{Aim}

The aim of this study is to carry out the screening of drought resistance degree and to determine the elements of individual productivity of the isogenic for genes, controlling of type and pace of wheat development, lines and soybean NILs with different photoperiodic reaction (sensitivity).

\section{Materials and methods}

\section{1. The plant material}

The objects of study are the model system represented by monogenic dominant nearly isogenic lines (NILs) of the genes PPD system of soft wheat Triticum aestivum L., created in genotype variety Mironovskaya 808 - three genotypes (PPD-Dla, PPD-Bla, PPD-Ala) and monogenic dominant nearly isogenic lines (NILs) on the genes $E E$ system of soybean Glycine max (L.) Merr., created in gene pool of variety Clark - too genotypes $\left(E_{1} E_{2} E_{3} E_{4} e_{5} E_{7}\right.$ and $\left.E_{1} E_{2} E_{3} E_{4} E_{5} E_{7}\right)$.

Isogenic lines (NILs) are a convenient model for physiological and genetic studies since they are different from each other only by the state of one gene locus (dominant/recessive) and have a distinct phenotypic response. These genetic systems control the photoperiodic sensitivity/insensitivity (photoperiodic neutral) of soft wheat Triticum aestivum L. (genes PPD) and soybean Glycine max (L.) Merr. (EE genes).

\section{2. Field experiments}

To identify the photoperiodic response of the investigated lines, during 2012-2014 the field experiments have been carried out in the experimental section of the Department of Plant and Microorganism Physiology and Biochemistry, V. N. Karazine Kharkiv National University $\left(50^{\circ} \mathrm{N}\right.$, $36^{\circ} 16^{\mathrm{E}} \mathrm{E}$ ). The plants grew under optimal timing of spring planting 10.04-20.04. Sowing has been carried out manually on the area of $1 \mathrm{~m}^{2}$ plots in a three replicate randomized complete block for each variant of the experiment. The tillering phase for wheat and third true leaf stage of soybean one part lines were exposed to short photoperiod (9 hours) for 14 days, and the control grew under 
natural long-day during (16 hours) the entire experiment. A short day has been created by the dimming of plants by light-proof booths from 18.00 to 9.00 hours.

\section{3. Phenotyping Measurements}

Phenotyping is determined length of the period from shoots to the earing (PSE) in wheat and duration of the period from shoots to flowering (PSF) in soybean (Table 1). After harvesting of the plants the individual elements of productivity have been determined: plant height, ear length, grain weight from the ear, number of grains per ear and weight of 1000 grains for wheat and plant height, number of lateral branches, number of beans, number of grains and weight of 1000 grains for soybeans (Table 2).

\section{4. Laboratory vegetation experiments}

To determine the drought tolerance level three methods have been used:

- rapid analysis of seed germination under artificial drought;

- inhibition of biomass accumulation in soil drought;

- accumulation of proline in the leaves under water stress in vegetative experiments in vivo.

1. Rapid analysis: drought tolerance has been assessed by the surveyed lines seed ability to germinate at the higher osmotic pressure in the $20 \%$ mannitol solution. This method simulates the lack of moisture in the soil at the stage of sowing-shoots. Seed germination has been determined by State Standard of Ukraine on the quality of seeds (Table 3).

2. Evaluation of growth inhibition and biosynthetic processes. The drought has been modeled in a growing experiment. Plants have been grown in soil culture in 5-liter plastic containers, 15 and 10 wheat plants soybean plants in each pot. Each line has been grown in 6 pot under $22 / 18{ }^{\circ} \mathrm{C}$ (day/night), 15-20 kLx illumination, at 16-hour photoperiod at $70 \%$ FMC - field moisture capacity of the soil. A month of cultivation later in $50 \%$ of containers ( 3 for each line), the conditions of soil drought by stopping irrigation has been created. Soil moisture has been adjusted to $30 \%$ FMC - field moisture capacity of the soil. In such moisture conditions plants grew for 2 weeks. At the end of the period the growth reaction, accumulation of biomass in plants in the control (70\% FMC) and experiments (30\% SMC) test have been measured (Table 4).

Hydration leaves (RWC - relative water content) was determined by the formula

$$
\mathrm{RWC} \%=\frac{\mathrm{Md}-\mathrm{Mw}}{\mathrm{Mw}} \times 100
$$

where Mw - wet weight, Md - dry weight (Table 5).

3. Evaluation of the proline content in the leaves. Proline content has been determined in the leaves tier 2-3 from the top that completed the growth [14] (Table 6).

Using indicators of rapid analysis, growth reactions of biomass and proline content, the drought tolerance has been calculated as the ratio of indicators under drought to the control indices and expressed by a percentage (Table 7).

\section{5. Statistical analysis}

Totally, three series field, of biological laboratory and greenhouse experiments have been in triplicate. Table 1, 2 show the average and standard deviation determinations $(\mathrm{x} \pm \mathrm{S})$. Significant differences between the variants of experiments (Table 1, 2) were evaluated by t-test (Student) at a significance level $P \leq 0,05$. Statistical analysis of the results shown in Tables $3-7$, carried out by one-way ANOVA. Differences between the experimental variants were assessed by LSD (the least significant difference) at a significance level $\mathrm{P} \leq 0,05$ using Excel 2010.

\section{Results}

To identify the possible connection of the photoperiodic sensitivity of the studied lines with drought resistance the experiments have been carried out to determine their response to changes in photoperiod. 
The results have shown that all investigated wheat lines have transited to heading significantly later under short photoperiod than under natural long days (Table 1). Therefore, a quantitative long-day reaction for all lines has been showed.

Table 1

Phenotyping isogenic lines NILs of wheat Triticum aestivum L. and soybean Glycine max (L.) Merr. in conditions of a short day (SD) and a natural long day (LD) (field experiment)*

\begin{tabular}{|c|c|c|c|c|c|}
\hline \multirow[t]{3}{*}{ Isoline } & \multirow[t]{3}{*}{$\begin{array}{l}\text { Genotype } \\
\text { NILs }\end{array}$} & \multicolumn{2}{|c|}{$\begin{array}{l}\text { Period shoots-earing (PSE) for wheat and the period of } \\
\text { shoots-flowering (PSF) for soybeans, days }\end{array}$} & \multirow{3}{*}{$\begin{array}{c}\text { Changing PSE } \\
\text { and PSF at SD, } \\
\text { days }\end{array}$} & \multirow[t]{3}{*}{$\begin{array}{l}\text { Photoperiodic } \\
\text { sensitivity }\end{array}$} \\
\hline & & 16 hours & 9 hours & & \\
\hline & & \multicolumn{2}{|c|}{ NILs Triticum aestivum L., variety Mironovskaya 80} & & \\
\hline Ppd 1 & PPD-D1a & $128 \pm 3$ & $147 \pm 3$ & +15 & weak PPDS \\
\hline Ppd 2 & PPD-B1a & $134 \pm 2$ & $153 \pm 3$ & $+19 * *$ & strong PPDS \\
\hline Ppd 3 & PPD-Ala & $125 \pm 2$ & $137 \pm 2$ & +12 & weak PPDS \\
\hline \multicolumn{6}{|c|}{ NILs Glycine max (L.) Merr., variety Clark } \\
\hline L65-3366 & $\mathrm{E}_{1} \mathrm{E}_{2} \mathrm{E}_{3} \mathrm{E}_{4} \mathrm{e}_{5} \mathrm{E}_{7}$ & $106 \pm 5$ & $63 \pm 2$ & -43 & strong PPDS \\
\hline L71-920 & $\mathrm{e}_{1} \mathrm{e}_{2} \mathrm{e}_{3} \mathrm{E}_{4} \mathrm{e}_{5} \mathrm{E}_{7}$ & $50 \pm 2$ & $46 \pm 1$ & $-4 * *$ & PPDN \\
\hline
\end{tabular}

Notes: NILs - near isogenic lines, SD - short day, PSE - period shoots-earing, PSF-period of shoots-flowering, PPDS-photoperiodic sensitivity; PPPN - photoperiodic neutral; * - data are presents $x \pm S x$; ${ }^{* *}$ - the difference are significant at $P \leq 0,05$

However, the line PPD Ala delayed transition to heading under short day to a lesser degree than lines $P P D D 1 a$ and $P P D$ B $1 a$, i. e., it was the least photoperiodically sensitive among the studied lines. Determination of photosensitivity of soybean isogenic lines has shown that they have differed considerably in the rate of development, both under the day long and short day (Table 1). Thus, under natural long day line $L$ 65-3366 has bloomed on 50-56 days later than the line L 71-920. Moreover, under short-day the line $L$ 65-3366 has accelerated transition to flowering on 43 days, while the line $L 71-920$ has bloomed in the same terms as under long day (Table 1). Consequently, the line $L$ 65-3366 has reacted to the reduced photoperiod as a typical short-day plant, while the line $L 71-920$ - as a neutral photoperiodic plant.

Thus, the present results show that the tested lines significantly differ by photoperiodic sensitivity which is determined by the $P P D$ genes in wheat and the $E E$ genes in soybean that is dominant and/or recessive specific loci of these genes. Our results confirm the data obtained by us earlier.

The main criterion of plant resistance to drought is the level of productivity under stress. To determine the possible link between drought and productivity of studied lines with different photoperiodic sensitivity, we have investigated the process of yield structure elements formation of isogenic lines during a long day in the field experiments.

The results of experiments of wheat lines (Table 2) have shown that plant height, ear length, the number of grains per ear and weight of grain per spike in line $P P D-B 1 a$ are larger than the lines $P P D-A 1 a$ and PPD-DIa. However, PPD-Ala line has the maximum weight of 1000 grains. This suggests that grain productivity $P P D-A 1$ l line with low photoperiod sensitivity is higher due to the larger grain size. Presumably, these differences could be related to the genotype of the studied lines with $P P D$ genes, i. e. with different levels of their photoperiodic sensitivity.

Determination of the plant elements of soybean isogenic lines has shown (Table 2) that the short-day plants of the line $L$ 65-3366 have high height and, conversely, the smaller number of beans, grains and grain weight per plant and weight of 1000 grains than the PPDN (photoperiodic neutral) plants of the line $L$ 71-920. This suggests that the efficiency of the studied soybean lines could be determined by a certain state (dominant and/or recessive) of $E$-series genes, which define the photoperiodic sensitivity of the lines. 
Table 2

Elements of the structure and the individual productivity of NILs of wheat Triticum aestivum L. and soybean Glycine max (L.) Merr. (field experiment)*

\begin{tabular}{|c|c|c|c|c|c|}
\hline \multirow{3}{*}{ Isoline } & \multirow{3}{*}{ Plant height, cm } & \multirow{2}{*}{$\begin{array}{l}\text { The length of the ear (wheat), } \\
\text { cm/number of beans (soybeans), pcs. }\end{array}$} & \multirow{2}{*}{$\begin{array}{l}\text { Grains per ear/on } \\
\text { the plant, pcs. }\end{array}$} & \multicolumn{2}{|c|}{ Grain weight g } \\
\hline & & & & with plant & 1000 pes. \\
\hline & & \multicolumn{4}{|c|}{ NILs Triticum aestivum L., variety Mironovskaya 808} \\
\hline Ppd 1 & $87,5 \pm 3,5$ & $5,2 \pm 0,2$ & $26,0 \pm 1,1$ & $1,3 \pm 0,05$ & $41,4 \pm 2,0$ \\
\hline Ppd 2 & $95,2 \pm 4,1^{* *}$ & $7,8 \pm 0,3 * *$ & $36,4 \pm 1,2 * *$ & $1,5 \pm 0,07 * *$ & $35,2 \pm 1,3 * *$ \\
\hline Ppd 3 & $89,9 \pm 3,1$ & $6,8 \pm 0,2$ & $26,8 \pm 0,9$ & $1,3 \pm 0,06$ & $43,7 \pm 2,2$ \\
\hline \multicolumn{6}{|c|}{ NILs Glycine max (L.) Merr., variety Clark } \\
\hline L65-3366 & $136,3 \pm 6,5$ & $9,2 \pm 0,5$ & $37,2 \pm 1,7$ & $4,8 \pm 1,5$ & $66,0 \pm 3,3$ \\
\hline L71-920 & $80,1 \pm 4,3$ & $17,4 \pm 3,2 * *$ & $41,2 \pm 1,9^{* *}$ & $6,1 \pm 1,5^{* *}$ & $149,1 \pm 5,7^{* *}$ \\
\hline
\end{tabular}

Notes: NILs-near isogenic lines; * - data are presents $x \pm S x ; * *$ the difference are significant at $P \leq 0,05$

Thus, the obtained results suggest that the lines of both cultures with reduced photoperiodic sensitivity (photoperiodic neutral) have the ability to generate higher grain productivity than the lines with high photoperiodic sensitivity.

In connection with the all stated above, a question arises about a possible link between the isolines revealed features and their drought tolerance. One of the important mechanisms of drought resistance is the ability of seeds to germinate together with a low level of humidity in the soil. To clarify this ability in our experiments, drought has been simulated by germination of the seeds of the studied lines on $20 \%$ mannitol solution. The results have shown (Table 3) that PPD-Ala line has the highest seed germination among the wheat lines, and among soybean lines - Line $L$ 71-920. Thus, rapid analysis of results has shown that both crop seed lines with reduced photoperiod sensitivity have a higher germination stage to drought than photoperiodic lines with increased sensitivity (Table 3).

Table 3

Influence of an artificial drought on seed germination of isogenic lines of wheat Triticum aestivum L. and soybean Glycine max (L.) Merr. (rapid analysis), \%

\begin{tabular}{|c|c|c|c|c|}
\hline \multirow[b]{2}{*}{ Isogenic line } & \multicolumn{3}{|c|}{ Seed germination, $\%$} & \multirow{2}{*}{$\begin{array}{c}\text { Drought } \\
\text { resistance seeds, \% }\end{array}$} \\
\hline & Genotype & The control, $\left(\mathrm{H}_{2} \mathrm{O}\right)$ & $\begin{array}{l}\text { The experiment, } \\
\text { (20\% mannitol) }\end{array}$ & \\
\hline \multicolumn{5}{|c|}{ NILs Triticum aestivum L., variety Mironovskaya 808} \\
\hline Ppd 1 & Ppd-Dla & 100,00 & 33,00 & 33,00 \\
\hline Ppd 2 & Ppd-Bla & 99,00 & 29,00 & 29,29 \\
\hline Ppd 3 & Ppd-Ala & 100 & 39,00 & 39,00 \\
\hline & & 2.22 & 4.42 & 4.45 \\
\hline \multicolumn{5}{|c|}{ NILs Glycine max (L.) Merr., variety Clark } \\
\hline L65-3366 & $\mathrm{E}_{1} \mathrm{E}_{2} \mathrm{E}_{3} \mathrm{E}_{4} \mathrm{e}_{5} \mathrm{E}_{7}$ & 61,65 & 29,95 & 48,58 \\
\hline L71-920 & $\mathrm{e}_{1} \mathrm{e}_{2} \mathrm{e}_{3} \mathrm{E}_{4} \mathrm{e}_{5} \mathrm{E}_{7}$ & 93,30 & 86,60 & 92,84 \\
\hline & & 9,34 & 14,5 & 12,8 \\
\hline
\end{tabular}

Notes: NILs - near isogenic lines

An integral indicator of plant life process under a variety of environmental conditions, including drought, is the biosynthetic processes, characterized by the accumulation of biomass. Determination of this parameter has shown in the model growing experiment (Table 4) that plant biomass of the isogenic lines of wheat and soybean decreased under the influence of drought (30\% FMC) during 2 weeks. 
Table 4

Effect of soil drought on the accumulation of biomass of isogenic lines of wheat Triticum aestivum L. and soybean Glycine max (L.) Merr. (growing experiment)

\begin{tabular}{|c|c|c|c|c|}
\hline \multicolumn{5}{|c|}{ Dry weight of one the plant, $g$} \\
\hline Isogenic line & Genotype & The control, $70 \%$ FMC & $\begin{array}{c}\text { The experiment, } 30 \% \\
\text { FMC }\end{array}$ & Drought resistance plants, $\%$ \\
\hline \multicolumn{5}{|c|}{ NILs Triticum aestivum L. variety Mironovskaya 808} \\
\hline Ppd 1 & Ppd-D1a & 1,31 & 0,78 & 59,54 \\
\hline Ppd 2 & Ppd-B1a & 1,67 & 0,97 & 58,08 \\
\hline Ppd 3 & Ppd-Ala & 1,16 & 1,00 & 86,21 \\
\hline & & 0.27 & 0.12 & 4.45 \\
\hline \multicolumn{5}{|c|}{ NILs Glycine max (L.) Merr., variety Clark } \\
\hline L65-3366 & $\mathrm{E}_{1} \mathrm{E}_{2} \mathrm{E}_{3} \mathrm{E}_{4} \mathrm{e}_{5} \mathrm{E}_{7}$ & 1,64 & 1,34 & 81,91 \\
\hline L71-920 & $\mathrm{e}_{1} \mathrm{e}_{2} \mathrm{e}_{3} \mathrm{E}_{4} \mathrm{e}_{5} \mathrm{E}_{7}$ & 2,67 & 2,49 & 93,23 \\
\hline & & 1.04 & 0.58 & 5.63 \\
\hline
\end{tabular}

Note: NILs - near isogenic lines; FMC-field moisture capacity of the soil

However, the level of reduction was different. Thus, in wheat line $P P D-A 1 a$ with a reduced photoperiodic sensitivity the plant weight has been decreased only to $0.16 \mathrm{~g}$ (14\% relative to control - $70 \%$ FMC) under $30 \%$ FMC. In PPDN soybean lines $L 71-920$ decrease has been either $0.16 \mathrm{~g}$ (6\% compared to control - $70 \%$ FMC). While the SDP line L 65-3366 has weight $0.30 \mathrm{~g}$ (18 $2 \%$ relative to control $-70 \%$ FMC) (Table 4). These results indicate that the lines with reduced PPPN are characterized by reducing properties of the biosynthetic processes measure during the drought in lesser extent than photoperiodic sensitivity lines.

Hydration of leaves characterizes the biocolloids ability to retain water during the drought, which is important to ensure the flow of photosynthesis and other physiological and biochemical processes under stress [15]. The definition of this indicator in plants of the isogenic lines has shown that under drought hydration of leaves decreased in all lines (Table 5). However, this reduction of the line of PPD-Ala amounted to about $10.7 \%$ while the lines PPD-Dla and PPD-B1a are 13.3 and $15.2 \%$ respectively. Consequently, the leaves of the line with lower PPDS (photoperiodic sensitivity) have a higher water-holding capacity than the leaves of the line with a higher PPDS.

Table 5

Hydration (RWC) leaves isogenic lines of wheat Triticum aestivum L. and soybean Glycine max (L.) Merr. (vegetation experiment), \%

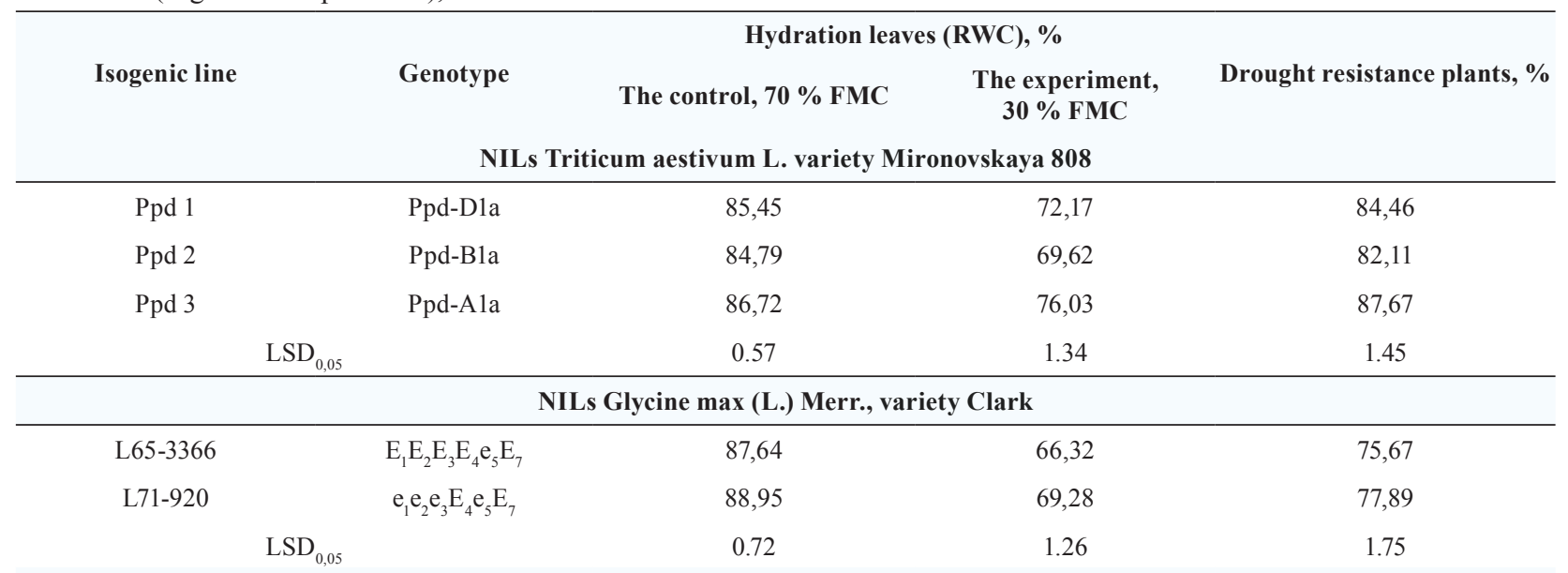

Notes: NILs - near isogenic lines; FMC - field moisture capacity of the soil; RWC-relative water content 
It is very important that proline synthesis among other mechanisms, ensure the resistance of plants to drought. Proline has osmolyte function under stress as well as an antioxidant and a membrane protector [16].

Given the above, we have studied the drought effect on the content of proline in the leaves of the investigated lines under its growing experiment modeling. The results of the proline content in leaves of wheat lines after a 2-week drought have showed that in all lines the content of present amino acid has greatly increased (Table 6). However, to the greatest extent, this increase has been in the PPD-Ala line with the lowest PPDS (Table 6).

\section{Table 6}

The effect of drought on the content of free proline in the leaves of isogenic lines of wheat Triticum aestivum L. and soybean Glycine max (L.) Merr. (growing experiment)

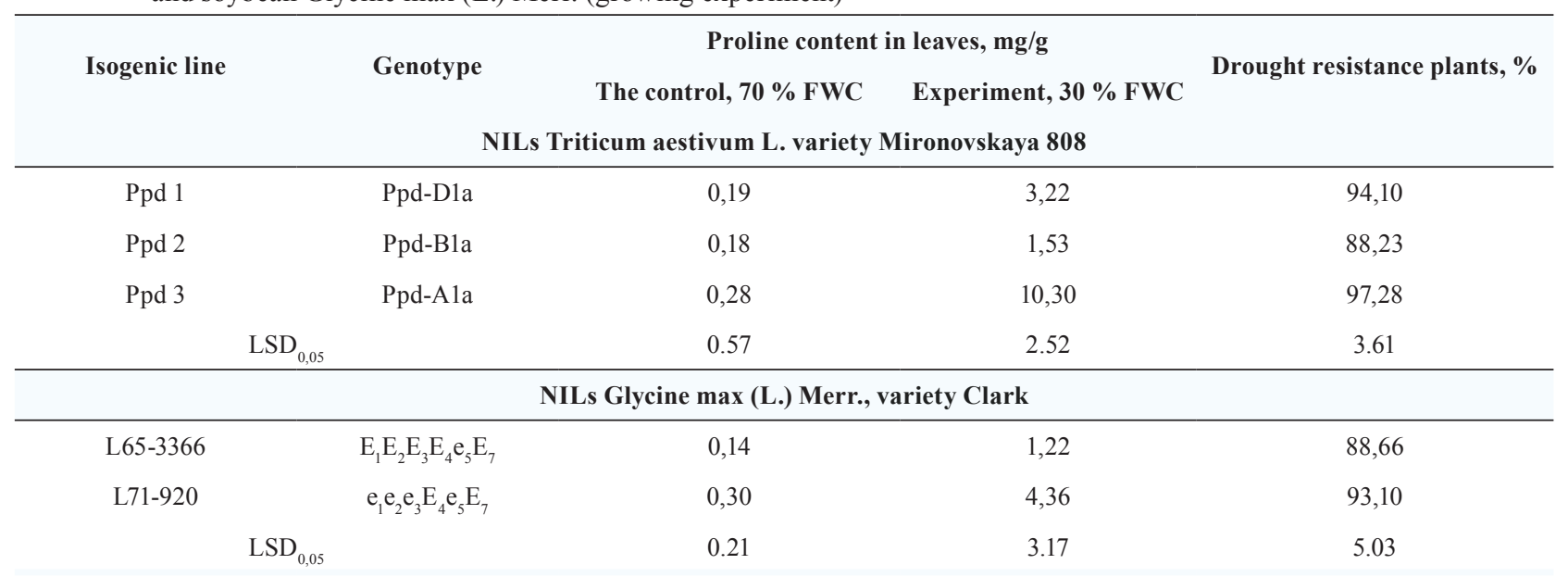

Note: NILs - near isogenic lines; FMC - field moisture capacity of the soil

A similar drought effect on the content of proline has been detected in soybean isogenic lines. Both lines proline content has increased under the influence of drought, but PPS line was almost four times higher than the SDP line (Table 6). Thus, wheat and soybean lines with reduced PPDS can synthesize proline more intensively under drought than the lines with increased PPDS.

\section{Discussion}

Table 7 summarizes the obtained results of drought resistance of the studied lines. The results are presented as a percentage change in the level of the investigated processes under the influence of drought, relative to the control. These data show that all indicators of the lines with a low PPDS - wheat PPD-Ala and soybean $L$ 71-920 - are higher than in the lines with increased PPDN. These indicators reflect the drought resistance of lines at different levels of their organization: germination, biomass accumulation, water content of leaves, proline content. This suggests that the drought resistance of the investigated lines is associated with their photoperiodic sensitivity. During the explanation of possible drought resistance mechanisms of researched wheat and soybean lines we revealed that germination of seeds under the conditions of lack of moisture depends on the content of protein in them, biomass synthesis, hydration of leaves, proline synthesis connected with the character and intensity of metabolic processes in plants.

We showed earlier, that isogenic by genes $P P D$ lines of wheat and isogenic by genes $E E$ lines of soybeans differ by the intensity of carbohydrates and nitric metabolism, ferment activity and balance of phytohormones.

In our opinion, the connection between draught resistance and photoperiodic sensitivity of lines could be the following. Different levels of ability of seed germination of the lines with different photoperiodic sensitivity could be associated with the differences between them by the biochemical composition of the grain. So we have shown the protein levels in the grain of wheat isogenic lines with different levels of photoperiod reaction [17], and soybean varieties with differ- 
ent photoperiodic reaction [18]. It is known that the initial stages of seed germination are associated with biocolloids swelling, including degumming of wheat endosperm protein at the soybean cotyledons. One of the reasons of higher isogenic lines seed germination with reduced PPDS could be higher level of protein in them. It is also likely that this could be connected with different protein composition, which could depend on its hydrophilic [8].

Table 7

Drought resistance NILs of wheat variety Mironovskaya 808 and NILs of soybean variety Clark, \%

\begin{tabular}{|c|c|c|c|c|}
\hline \multirow{2}{*}{ Isogenic line } & \multicolumn{4}{|c|}{ Indicators drought resistance, $\%$ of control } \\
\hline & Seed germination & Biomass accumulation & Leaf water content & Proline content \\
\hline \multicolumn{5}{|c|}{ NILs Triticum aestivum L., variety Mironovskaya 808} \\
\hline PPD-D1a & 33,23 & 59,54 & 84,46 & 94,10 \\
\hline PPD-B1a & 28,95 & 58,08 & 82,11 & 88,23 \\
\hline PPD-A1a & 39,00 & 86,21 & 87,67 & 97,28 \\
\hline $\mathrm{LSD}_{0,05}$ & 4.45 & 4.45 & 1.45 & 3.61 \\
\hline \multicolumn{5}{|c|}{ NILs Glycine max (L.) Merr., variety Clark } \\
\hline L65-3366 & 48,58 & 81,91 & 75,67 & 88,66 \\
\hline L71-920 & 92,84 & 93,23 & 77,89 & 93,10 \\
\hline $\mathrm{LSD}_{0,05}$ & 12,8 & 5.63 & 1.75 & 5.03 \\
\hline
\end{tabular}

Note: NILs - near isogenic lines

The fact that the drought inhibits the accumulation of biomass in lines with reduced PPDN to a lesser degree could probably be explained by the greater "lability" of their metabolic processes. We have shown that the wheat and soybean lines change the intensity of the carbohydrate and protein metabolism, as well as the status of phytohormones under the influence of short photoperiod [19]. This reduces the accumulation of biomass, but the speed of the transition to the generative state (the heading and flowering of wheat and soybean), depending on the photoperiod of the line with reduced PPDS, remained virtually unchanged. It is logical to assume in this case that reduced PPDS line is capable of changing the level of physiological and biochemical processes in this way. This provides energy and plastic material for the normal passing of different intensity morphological processes of environmental factors, including the response to drought. Lines with increased PPDS either do not have this property or it is expressed to much lesser degree than in line with reduced PPDS.

In our view, the higher level of productivity in wheat and soybean isogenic lines with low PPDN is also related to their ability to maintain a sufficiently high level of metabolic processes in the changing environment, including during drought. It is likely that the lines with low photoperiodic sensitivity have higher water content in leaves, associated with the ability to support the metabolic processes during drought at a high level for the biosynthesis of macromolecules with a fairly high level of hydration. Under drought, a significantly higher increase of leaves proline content in lines with reduced photoperiod sensitivity could also be due to the fact that their intensity of metabolic processes, affecting the level of amino acids synthesis and including the proline, is higher under stress than those of lines with high photoperiodic sensitivity. The results of drought resistance of wheat and soybean isogenic lines are shown in Table 7. Analysis of these lines has shown that all used methods have given similar results, that is, wheat and soybean lines with low PPDS differ from lines with a high PPDS by higher levels of drought on seed germination with increased osmotic pressure of the external solution, biomass accumulation, hydration of the leaves and their content of proline. 


\section{Conclusion}

The experimental results have shown that wheat and soybeans isogenic lines under study have varied in photoperiodic sensitivity. Among the wheat lines, the line with the dominant gene $P P D-A 1 a$ has the lowest PPS, among soybean lines - L71-920. Our results confirm the literature data of the determination of wheat photoperiodic sensitivity genes $P P D[6,19]$ and soybean - EE genes $[7,12]$. Thus, photoperiodic sensitivity level depends on the state of these genes - dominant and/or recessive. The level of drought tolerance in the studied lines is connected with their photoperiodic sensitivity and, hence, with the genes $P P D$ (wheat) and $E E$ genes (soybean). The lines with reduced photoperiodic sensitivity have greater drought resistance than the lines with high photoperiodic sensitivity. This suggests that the photoperiodic sensitivity control genes could be involved in the mechanisms of wheat and soybean resistance to drought. The results show that the productivity of wheat and soybean lines with reduced PPDS is higher than in lines with high PPDS. It is likely that genes $P P D$ wheat and soybean $E E$ genes are involved in the regulation of productivity. The foregoing suggests that to create new varieties of wheat and soybean as a raw material the genotypes with lowered photoperiodic sensitivity or photoperiodic neutrality should be used

\section{Acknowledgments}

We would like to thank the Plant Breeding and Genetics Institute - the National Centre of Seeds and Cultivar Investigation of National Academia Agricultural Science of Ukraine, which has kindly provided us with seeds NILs cultivar Mironovskaya 808.

The authors are grateful to the National Center for Plant Genetic Resources of Ukraine for assistance in obtaining isogenic by $E$-genes of soybean lines from the USDA collection (Agricultural Research Service).

\section{References}

[1] Nezhadahmadi, A., Prodhan, Z. H., Faruq, G. (2013). Drought Tolerance in Wheat. The Scientific World Journal, 2013, 1-12. doi: 10.1155/2013/610721

[2] Cattivelli, L., Bald, P., Crosatti, C., Fonzo, N., Faccioli, P. et. al. (2002). Chromosome regions and stress-related sequences involved in resistance to abiotic stress in Triticeae. Plant Molecular Biology, 48, 649-665. doi: 10.1023/a:1014824404623

[3] Aprile, A., Mastrangelo, A. M., De Leonardis, A. M., Galiba, G., Roncaglia, E., Ferrari, F. et. al. (2009). Transcriptional profiling in response to terminal drought stress reveals differential responses along the wheat genome. BMC Genomics, 10 (1), 279. doi: 10.1186/1471-2164-10-279

[4] Collins, N. C., Tardieu, F., Tuberosa, R. (2008). Quantitative Trait Loci and Crop Performance under Abiotic Stress: Where Do We Stand? Plant Physiology, 147 (2), 469-486. doi: 10.1104/pp.108.118117

[5] Fleury, D., Jefferies, S., Kuchel, H., Langridge, P. (2010). Genetic and genomic tools to improve drought tolerance in wheat. Journal of Experimental Botany, 61 (12), 3211-3222. doi: 10.1093/jxb/erq152

[6] Kumar, S., Sharma, V., Chaudhary, S., Tyagi, A., Mishra, P., Priyadarshini, A., Singh, A. (2012). Genetics of flowering time in bread wheat Triticum aestivum: complementary interaction between vernalization-insensitive and photoperiod-insensitive mutations imparts very early flowering habit to spring wheat. Journal of Genetics, 91 (1), 33-47. doi: 10.1007/s12041-012-0149-3

[7] Cober, E. R., Molnar, S. J., Charette, M., Voldeng, H. D. (2010). A New Locus for Early Maturity in Soybean. Crop Science, 50 (2), 524. doi: 10.2135/cropsci2009.04.0174

[8] Joshi, R., Karan, R. (2013). Physiological, Biochemical and Molecular Mechanisms of Drought Tolerance in Plants. Molecular Approaches in Plant Abiotic Stress, 209-231. doi: 10.1201/b15538-14

[9] Distelfeld, A., Tranquilli, G., Li, C., Yan, L., Dubcovsky, J. (2008). Genetic and Molecular Characterization of the VRN2 Loci in Tetraploid Wheat. Plant Physiology, 149 (1), 245-257. doi: 10.1104/ pp.108.129353

[10] Trevaskis, B. (2010). Goldacre Paper: The central role of the VERNALIZATION1 gene in the vernalization response of cereals . Functional Plant Biology, 37 (6), 479. doi: 10.1071/fp10056

[11] Worland, A. J., Borner, A., Korzun, V. et. al. (1998). The influence of photoperiod genes on the adaptability of European winter wheats. Euphytica, 100, 385-394. doi: 10.1023/a:1018327700985 
[12] Cober, E. R., Morrison, M. J. (2009). Regulation of seed yield and agronomic characters by photoperiod sensitivity and growth habit genes in soybean. Theoretical and Applied Genetics, 120 (5), 1005-1012. doi: 10.1007/s00122-009-1228-6

[13] Khotyljov, L., Kaminskaya, L., Koren, L. (2002). Influence of genetic systems of Vrn and Ppd genes on the ecological adaptation of wheat and triticale. Pradzia. LEIDINIAL. Biologija, 4, 45-48.

[14] Carillo, P., Gibbon, Y. Protocol: Extraction and determination of proline. Protocols in ecological \& environmental plant physiology. Available at: http://prometheuswiki.publish.csiro.au/tiki-index. php?page $=$ Extraction + and + determination + of + proline

[15] Ingram, J., Bartels, D. (1996). The molecular basis of dehydration tolerance in plants. Annual Review of Plant Physiology and Plant Molecular Biology, 47 (1), 377-403. doi: 10.1146/annurev.arplant.47.1.377

[16] Szabados, L., Savouré, A. (2010). Proline: a multifunctional amino acid. Trends in Plant Science, 15 (2), 89-97. doi: 10.1016/j.tplants.2009.11.009

[17] Zhmurko, V., Avksentyeva, O., Bing, H. (2013). Influence of photoperiodic conditions on the development and content of nitrogenous compounds in the VRN NILs wheat Triticum aestivum L. Biologija, 59 (2). doi: 10.6001/biologija.v59i2.2756

[18] Aldal'in, H., Zmurko, V., and Avksentyeva, O. (2012). Seed protein and oil content of the soybean cultivars under different climatic condition (Glycine max (L.) Merr.). American-Eurasian Journal of Agricultural and Environmental Science, 12 (5), 603-607.

[19] Zhmurko, V., Avksentyeva, O., Zubrich, A. et. al. (2011). Effekty genov fotoperiodicheskoy chuvstvitelnosti (PPD i EE) i potrebnosti v yarovizatsii (VRN) na fiziologo-biokhimicheskiye u rasteniy. Fiziologia i biochimia plantelor, 3 (315), 72-79. 